\title{
Nuclear and chloroplast genetic structure indicate fine-scale spatial dynamics in a neotropical tree population
}

\author{
C Latouche-Hallé ${ }^{1}$, A Ramboer ${ }^{1}$, E Bandou ${ }^{2}, \mathrm{H} \mathrm{Caron}^{1}$ and A Kremer ${ }^{1}$ \\ ${ }^{1} I N R A$ Station de Recherches Forestières, Laboratoire de Génétique des Arbres Forestiers BP45 33611 Gazinet cedex, France; ${ }^{2} I N R A$ - \\ Recherches Forestières BP709 97387 Kourou cedex (French Guiana), France
}

\begin{abstract}
Dicorynia guianensis is a canopy tree, endemic to the tropical rain forest of French Guiana. We compared generational and spatial genetic structure for maternally and biparentally inherited markers in two cohorts (adult and seedling) in order to infer processes shaping the distribution of genetic diversity. The study was conducted on a 40 ha study plot located at Paracou near Kourou, where 172 adults trees and 375 saplings were sampled. Aggregation of trees was therefore suggested at different distances, ranging from 100 to $400 \mathrm{~m}$. There was a strong link between demographic and genetic spatial structures at small distances (less than $100 \mathrm{~m}$ ) that is likely to be the consequence of restricted seed dispersal. Genetic differentiation was more pronounced between spatial aggregates than between cohorts. Despite
\end{abstract}

the spatial differentiation, the species was able to maintain high levels of diversity for maternal genomes, suggesting rapid turnover of aggregates. Spatial autocorrelation was larger for chloroplast than nuclear markers indicating a strong asymmetry between pollen and seed flow. Fixation indices indicated a lower heterozygote deficiency for the adults, maybe because of gradual elimination of selfed trees. Genetic relatedness at lower distances was higher in adult trees than in saplings, as a result of generation overlapping in the adult cohort. Overall, our results confirm earlier biological knowledge about the dispersion mechanisms of the species, and lead to an enhanced role of spatial processes in the dynamics of genetic diversity of $D$. guianensis.

Heredity (2003) 91, 181-190. doi:10.1038/sj.hdy.6800296

Keywords: dicorynia guianensis; microsatellites; spatial analysis; genetic differentiation; gene flow; tropical tree

\section{Introduction}

The Guianan shield is one of the largest continuous areas of pristine lowland tropical rainforest in the world. It is characterized by a high species richness of local and regional endemism, particularly among the flora. Dicorynia guianensis Amshoff (Fabaceae) is an endemic canopy tree (Sabatier and Prevost, 1990) representing up to $10 \%$ of the Guianan forest stands (Bena, 1960). It is one of the most exploited species for timber wood in French Guiana. As is the general rule for tropical tree species, D. guianensis is characterized by a low density: seven and 35 trees per ha for adults and saplings, respectively (Bariteau, 1993). Moreover, D. guianensis has a patchy spatial distribution (Cabrera-Gaillard and Gignoux, 1990), which led to the use of a spatial approach to analysing genetic diversity.

Caron et al (1998) studied the mating system using allozymes and demonstrated that D. guianensis is mostly outcrossing. This study also showed heterogeneity of pollen clouds between patches. The same authors found that maternally inherited markers (chloroplast DNA, cpDNA) exhibited a strong spatial structure (Caron et al, 2000) and suggested that the maintenance of cpDNA

Correspondence: $H$ Caron, INRA Laboratoire de Génétique des Arbres Forestiers BP45 33611 Gazinet cedex, France.

E-mail: caron@pierroton.inra.fr

Received 22 July 2002; accepted 13 February 2003 polymorphisms in a patchy pattern was most likely a result of rapid turnover of extinction-colonization phases. In the present study, this approach was extended by combining a nuclear and chloroplast survey of genetic diversity within two different cohorts (adults and saplings) at the population scale. A total of six simple sequence repeats (SSR) developed by Latouche-Hallé et al (2002) were used to examine nuclear diversity. These multivariate markers are extremely powerful tools for describing fine-scale spatial structures (Streiff et al, 1998) and reconstructing gene flow (Streiff et al, 1999). Comparative analysis of nuclear and cytoplasmic diversity permits the separation of the impact of pollen and seed-mediated gene flow on the differentiation of populations (Ennos, 1994). Considering that the species is thought to be pollinated by large bees and that the seeds are dispersed by wind (Caron et al, 1998), it would be expected that asymmetric gene flow would result in different fine-scale spatial genetic structure for nuclear and chloroplast DNA markers.

The aim of this study was to depict the fine-scale spatial and generational genetic structures to infer the major genetic and ecological processes shaping the distribution of genetic diversity in D. guianensis. Therefore, three comparative approaches we implemented. First, demographic and genetic spatial structures were compared in order to identify spatial processes. Second, nuclear and cytoplasmic spatial structures were compared to evaluate the contribution of pollen and seed to 
local dispersion. Finally, the spatial genetic structure between the adult and sapling cohorts were compared in order to identify the processes modifying diversity during the lifetime of the trees.

\section{Materials and methods}

\section{Field site}

The field site is part of the Paracou experimental site (detailed description in Schmitt and Bariteau, 1990), which was established in 1984 in the tropical primary rain forest, $45 \mathrm{~km}$ west from Kourou, in French Guiana $\left(5^{\circ} 15^{\prime} \mathrm{N}, 53^{\circ} \mathrm{W}\right)$. The original aim of the Paracou experiment was to test different silvicultural regimes, to assess the impact of logging for most of the important exploited Guianan tree species. A total of 12 plots of 9 ha each were established. Systematic inventories (species, mapping, number, diameter) are carried out every two years on all adult trees greater than $10 \mathrm{~cm}$ in diameter at breast height (DBH). Since 1988 no silvicultural operations have been undertaken in Paracou.

\section{Sampling}

This study was conducted in a subset of the Paracou experimental site within four almost contiguous plots of 9 ha (Figure 1), representing in total an area of 40 ha $(650 \mathrm{~m}$ by $650 \mathrm{~m})$. The demographic sampling was subdivided into two cohorts and was exhaustive within each cohort. The adult cohort was composed of all trees greater than $10 \mathrm{~cm}$ DBH (CIRAD-forêt, personal communication). The sapling cohort consisted in the additional inventory of all the 2211 trees taller than $1 \mathrm{~m}$ but less than $10 \mathrm{~cm}$ DBH (CIRAD-forêt, personal communication).

For genetic analysis, the study material was restricted to two samples (Figure 2).

(i) The adult sample consisted of all trees greatest than $20 \mathrm{~cm}$ DBH present in the study area (172 individuals). By doing this, sampling was restricted to only potentially reproductively mature trees, as the minimum diameters of flowering and fruiting trees are 18.3 and $22 \mathrm{~cm}$, respectively (Caron et al, 1998). Prior incomplete knowledge based on the distribution of rare allozymes indicated that pollen can be dispersed over several hundreds of metres; result confirmed using microsatellites (Latouche-Hallé et al, submitted). As a result, the sampling should comprise a subset of a given population.

(ii) The sapling sample comprised two subsamples: a random sample throughout the study area, and an exhaustive sample in the central part of the study area. In the centre of the study area, all saplings present in a 1.8 ha area were genotyped (Figure 2). In total, 375 saplings were sampled.

Cambium tissue and leaf tissue were collected from each adult tree and sapling, respectively. Samples were frozen at $-50^{\circ} \mathrm{C}$ in the laboratory until DNA extraction.

\section{Molecular analysis}

Total genomic DNA was extracted from cambium (adults) and leaf (sapling) tissues following the procedure of Doyle and Doyle (1990), modified as described by Dumolin et al (1995). Six microsatellite loci were amplified by the polymerase chain reaction (PCR

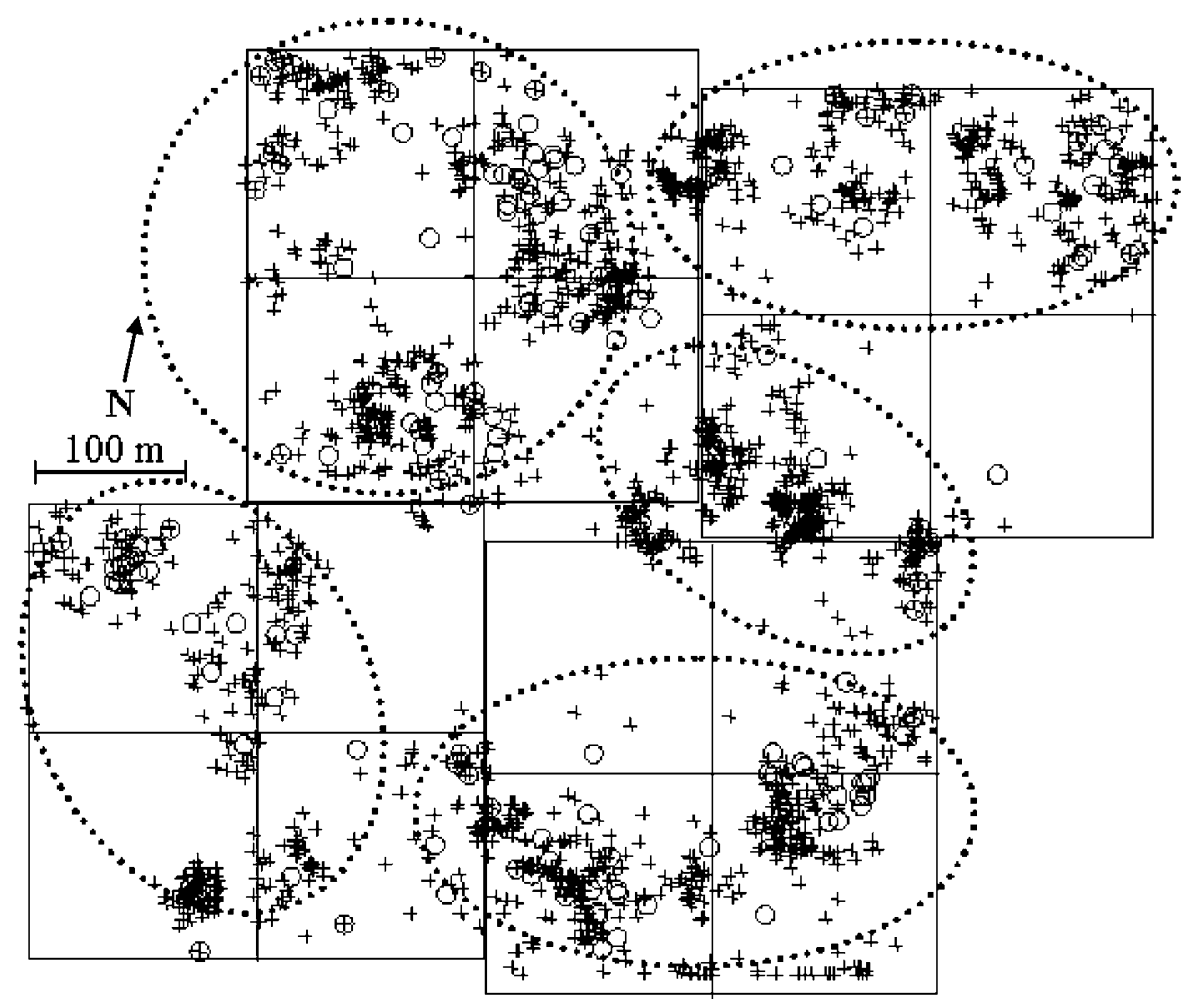

Figure 1 Distribution of the trees sampled in two cohorts for the analysis of the demographic spatial structure. $\bigcirc: 172$ adults (all trees having a DBH $>20 \mathrm{~cm}$ ) +: 2211 saplings (all trees taller than $1 \mathrm{~m}$ but less than $10 \mathrm{~cm} \mathrm{DBH)}$. Trees are clustered in five aggregates according to their spatial distributions (see text). 


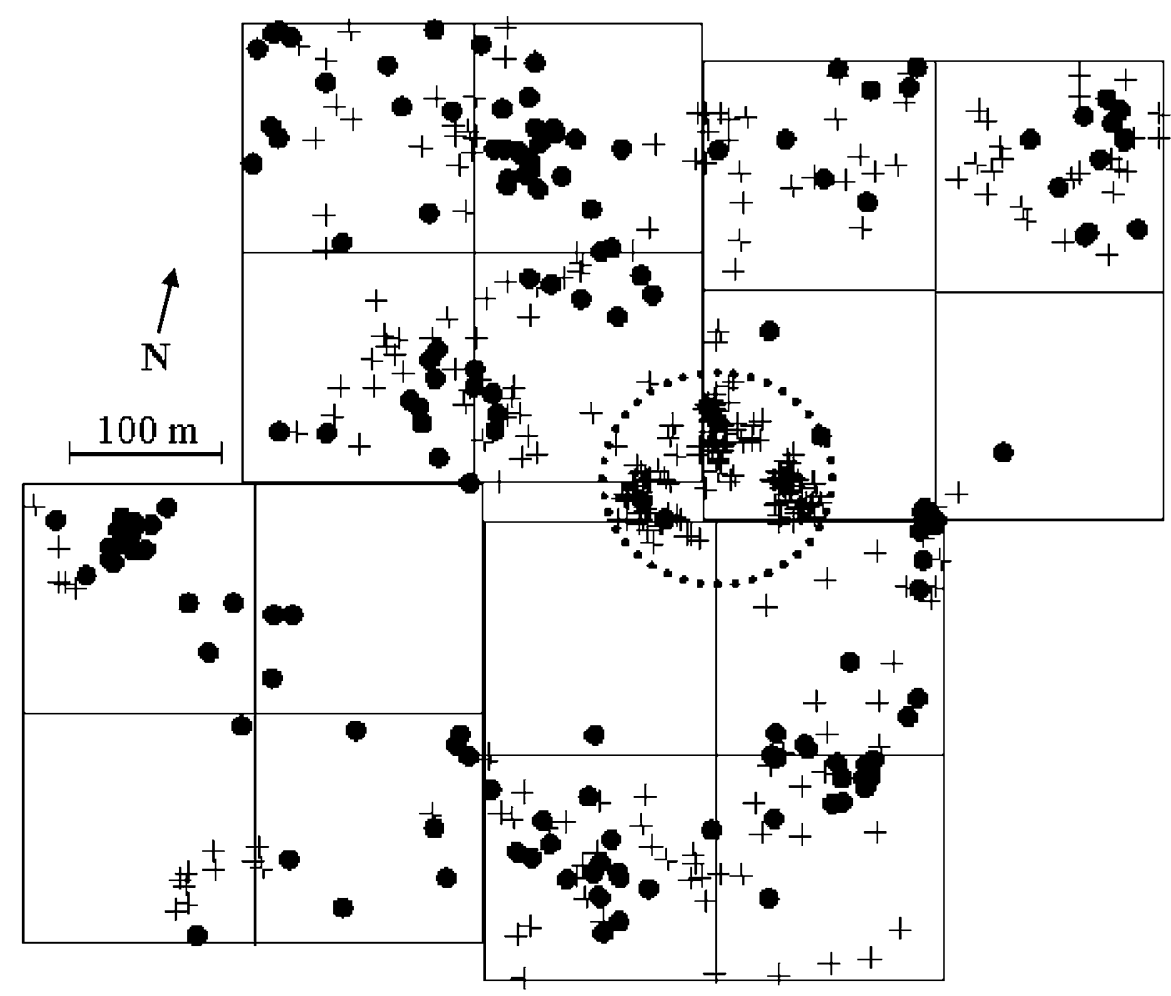

Figure 2 Distribution of the trees sampled in the two cohorts for the genetic diversity survey. $\bullet: 172$ adults (all trees having a DBH $>20 \mathrm{~cm}$ ), $+: 375$ saplings (all trees taller than $1 \mathrm{~m}$ but less than $10 \mathrm{~cm} \mathrm{DBH).} \mathrm{Saplings} \mathrm{were} \mathrm{randomly} \mathrm{selected,} \mathrm{except} \mathrm{in} \mathrm{the} \mathrm{central} \mathrm{part} \mathrm{of} \mathrm{the} \mathrm{plot,}$ where all saplings were genotyped.

Table 1 Primer pairs for chloroplast PCR-RFLP analysis

\begin{tabular}{|c|c|c|c|c|c|}
\hline & $\begin{array}{l}\text { Primer seuence } \\
\quad\left(5^{\prime} \rightarrow 3^{\prime}\right)\end{array}$ & Reference & $\begin{array}{l}\text { Annealing } \\
\text { temp. }\left({ }^{\circ} \mathrm{C}\right)\end{array}$ & $\begin{array}{l}\text { Elongation } \\
\text { time (min) }\end{array}$ & $\begin{array}{l}\text { Size in } \\
\text { tobacco }(b p)\end{array}$ \\
\hline $\begin{array}{l}\text { Upper Trn T } \\
\text { Lower C2 }\end{array}$ & $\begin{array}{l}\text { gcccttttaactcagtggta } \\
\text { ccctccgtaaccagtcat }\end{array}$ & $\begin{array}{l}\text { Dumolin-Lapegue et al. }(1997 \mathrm{a}, \mathrm{b}) \\
\text { This study }\end{array}$ & 52 & 2 & 1366 \\
\hline
\end{tabular}

Latouche-Hallé et al, 2002). The reaction solution $(12.5 \mu \mathrm{l})$ contained each of the four dNTPs $(100 \mu \mathrm{M}), 0.2 \mu \mathrm{M}$ of each primer, $1.8 \mathrm{mM}$ of $\mathrm{MgCl}_{2}, 2.5 \mu \mathrm{l}$ of $10 \mathrm{X}$ reaction buffer $\left(670 \mathrm{mM}\right.$ Tris-Hcl pH $8,160 \mathrm{mM}\left(\mathrm{NH}_{4}\right)_{2} \mathrm{SO}_{4}, 0.1 \%$ Tween-20), $3 \mathrm{ng}$ of genomic DNA and 0.2 units of Taq DNA polymerase Sylverstar (Eurogentec, France). The primers were labelled with the infra-red fluorescent dye IR800. Cycling conditions were stated by denaturation at $94^{\circ} \mathrm{C}$ for $4 \mathrm{~min}, 35$ cycles of $45 \mathrm{~s}$ at $94^{\circ} \mathrm{C}, 45 \mathrm{~s}$ at the annealing temperature $\left(53-60^{\circ} \mathrm{C}\right.$ according to the locus), and $45 \mathrm{~s}$ at $72^{\circ} \mathrm{C}$, with a final extension step of $8 \mathrm{~min}$ at $72^{\circ} \mathrm{C}$. Following amplification, $2 \mu \mathrm{l}$ of PCR product were mixed with $5 \mu \mathrm{l}$ of loading buffer ( $78 \%$ formamide, $10 \mathrm{mM}$ EDTA pH 7.6, $0.1 \%$ bromophenol blue and $0.1 \%$ xylene cyanol), heated for $3 \mathrm{~min}$ at $75^{\circ} \mathrm{C}$ and then set on ice. A measure of $0.8 \mu$ l of the denatured SSR solution was loaded onto a LI-COR automated sequencer on a $25 \mathrm{~cm} 8 \%$ acrylamide/bisacrylamide (19:1) denaturating gel.

One PCR-RFLP cpDNA combination (TC2 primer/Taq I), that has revealed polymorphism in D. guianensis in the Paracou stand (Caron et al, 2000), was used following the Dumolin-Lapègue et al $(1997 \mathrm{a}, \mathrm{b})$ protocol. Amplification problems due to the large length of the PCR fragment were resolved by designing nested primers to obtain smaller fragment (1366 vs $3236 \mathrm{bp}$, Table 1).

Demographic spatial distribution of trees

Spatial coordinates of all adult trees and 2211 saplings present in the study area were available. We used the second-order neighbourhood analysis of Ripley (1976) (K function) to analyse the spatial distribution of the trees. The $K(r)$ function is proportional to the average number of neighbours located a distance $r$ from any given tree (Pelissier and Goreaud, 2001). Given a density $\lambda$ of trees the following expression holds:

$\lambda K(r)=E$ (number ofneighbours located at distance

$$
\leq r \text { to a given point (tree)) }
$$

The $K$ statistic could be compared to its expectation under the null hypothesis of complete spatial randomness, which follows a Poisson process. For example, under the null hypothesis, the expected number of neighbouring trees at a distance $r$ from any point is $\lambda \pi r^{2}$ and $K(r)$ is then $\pi r^{2}$. If trees are aggregated there are more neighbouring trees at distance $r$ and $K(r)$ is greater than $\pi r^{2}$. Conversely, if trees are regularly distributed 
there will be fewer neighbours at a given distance $r$, hence $K(r)$ will be lower than $\pi r^{2}$. When the $K$ values are plotted as a function of $r$, the curve $K(r)$ is expected to be a parabola. Hence the value of $K$ depends on the distance $r$. To avoid this difficulty, the $L$ transformation has been used (Besag, 1977). The $L$ function (equation 2) has the same expectation under the null hypothesis $(L(r)=0)$ regardless of the $r$-value (Besag, 1977a,b).

$$
L(r)=\sqrt{\frac{K(r)}{\pi}}-r
$$

$L(r)$ is positive for an aggregated pattern and negative for a regular spatial distribution of trees. As the theoretical distribution of the estimator of the function $L(r)$ is unknown, Monte Carlo simulations were used to test significant deviation at the $5 \%$ significance level (Besag, 1977a,b). Analyses were performed by ADS in ADE 4 (package 'Spatial Data Analysis' in the software 'Ecological Data Analysis'; Thioulouse et al (1997); http://pbil.univ-lyon1.fr/ADE4/Download.html).

\section{Nuclear and cpDNA diversity Analyses}

Statistical analysis of microsatellite data was performed using GENEPOP (version 3.3; Raymond and Rousset, 1995). Distributions of the observed allelic frequencies were computed for each locus. For each locus, allele number $(A)$, effective allele number $A_{e}=1 /\left(1-H_{\mathrm{e}}\right)$, mean number of alleles per locus and mean effective number of alleles per locus were calculated. The allelic richness $(A)$ of two cohorts was standardized to remove the bias due to population size using a rarefaction method (ElMousadik and Petit, 1996). Observed and expected heterozygosities (unbiased estimator of Nei, 1987) were calculated. $F_{\text {is }}$ (fixation index) were estimated according to Weir and Cockerham's (1984) method. A Student's $t$ test and a z-test were performed to compare allelic richness, $H_{\mathrm{e}}$, and $H_{\mathrm{o}}$ between adult and sapling cohorts. Departure from Hardy-Weinberg equilibrium was tested using the exact tests of Haldane (1954) and exact $P$ values were estimated without bias by the Markov chain method (Guo and Thompson, 1992). A global test across loci was constructed using Fisher's method (Sokal and Rohlf, 1994).

Genetic diversity statistics for maternally inherited cpDNA markers were calculated in similar manner as for nuclear diversity: haplotypic richness $(A)$, effective number of haplotypes $\left(A_{\mathrm{e}}\right)$, and within population diversity $\left(H_{\mathrm{s}}\right)$. These statistics were estimated by software (written in Fortran) that provide gene diversity and differentiation statistics for uniparentally inherited markers, following Nei's (1987) subdivision of genetic diversity.

\section{Spatial and generational genetic structure analyses}

F-statistics were used to measure hierarchical population structure (Weir and Cockerham, 1984). Subpopulations were defined according to (i) generational and (ii) spatial distributions.

(i) For the generational distribution, the two cohorts (adult vs sapling) were first considered. In addition, the adult cohort was subdivided into three classes according to diameter distributions (20-34, 34-50, and $>50 \mathrm{~cm}$ ).

(ii) For the spatial distribution, the population was subdivided into five patches according to the spatial distribution of all the 2383 individuals (adults and saplings) in the south block of Paracou (Figure 1).

For nuclear data, analyses were carried out using FSTAT V2.9.1. (Goudet, 1995). Jackknifing over loci was performed to estimate standard errors. Statistical tests were performed for each locus individually using permutations (2000 randomizations). For $\mathrm{F}_{\text {IS }}$, alleles were permuted among individuals within samples, for $\mathrm{F}_{\mathrm{IT}}$ alleles were permuted among samples, and for population differentiation $\left(\mathrm{F}_{\mathrm{ST}}\right)$, genotypes were randomized among samples (tested without assuming Hardy-Weinberg). The log-likelihood statistic, $G$ (Goudet et al, 1996) was used to classify genotypic contingency tables. Finally, tests for pairwise differentiation between subpopulations (not assuming $\mathrm{HW}$ ) were performed by randomly assigning multilocus genotypes between sample pairs.

For chloroplast data, within population $\left(H_{\mathrm{S}}\right)$, total population diversity $\left(H_{\mathrm{T}}\right)$ and differentiation $\left(G_{\mathrm{ST}}\right)$ were computed following Pons and Petit (1995). $\chi^{2}$ statistical tests were performed and $P$-values estimated to compare alleles frequencies.

Autocorrelation analyses were performed using Moran's indexes for both diploid nuclear (monolocus and multilocus) and haploid chloroplast data using SGS software (version 1.0 c Degen et al, 2001). This statistic measures correlation between spatial (sample coordinates) and genetic data. The analysis is based on classes of distances between pairs of individuals. The size $(r)$ and the number of distance classes $(k)$ were chosen such that all classes had approximately the same number of pairs. For a given class $i$ (ranging from 1 to $k$ ), Moran's index was calculated for all pairs of trees, whose Euclidean distance was between [ $(i-1) r ; i r]$. Deviations from random distribution of alleles were calculated by permutation tests, randomizing the redistribution of genetic data over the spatial coordinates of sampled points. Since the sample size of saplings was larger than that of the adults, and because of the unbalanced sampling of saplings (exhaustive sampling within the central area, and random elsewhere), the sample size of saplings was restricted to that of the adults by sampling the nearest sapling to each adult tree.

\section{Results}

\section{Demographic spatial distribution of trees}

For both cohorts, the $L$-function curves exhibited a divergence from the null-hypothesis of a random distribution of trees (Figure 3); positive values suggested that trees are distributed in aggregates. The $L$-function reached two maxima, at about $100 \mathrm{~m}$, and at about $400 \mathrm{~m}$. Aggregation of trees was therefore suggested at different sizes ranging between these two peak values, meaning that no precise size of aggregates can be distinguished in the data. The $L$ curves indicated that there is significant aggregation between 100 and $400 \mathrm{~m}$. Although there was an overall similarity of the $L$ curves for the two cohorts, the bimodality is sharper for the adults than for the 


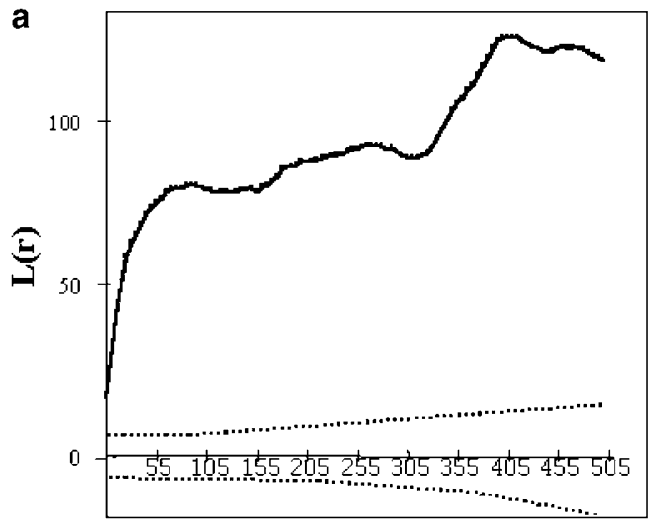

Distance r (m)

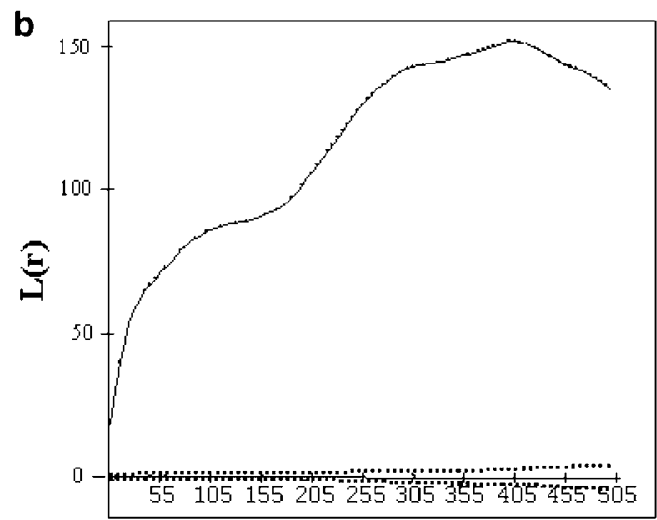

Distance $\mathbf{r}$ (m)

Figure 3 Variation of the $L(r)$-function according to distance $(r)$ : (a) adult trees, (b) saplings. The line corresponds to the observed data. The two dotted lines correspond to the $95 \%$ confidence interval envelope calculated by Monte-Carlo simulations.

Table 2 Nuclear genetic diversity statistics

\begin{tabular}{|c|c|c|c|c|c|c|c|c|}
\hline Loci & $\mathrm{n}$ & A & $\mathrm{A}_{e}$ & $\mathrm{~A}_{e} / \mathrm{A}$ & $\mathrm{H}_{o}$ & $\mathrm{H}_{e}$ & $\mathrm{~F}_{I S}$ & P-value of exact test \\
\hline \multicolumn{9}{|l|}{ Adults } \\
\hline$D g 1$ & 172 & 6 & 1.64 & 0.27 & 0.366 & 0.390 & 0.061 & 0.0056 \\
\hline$D g 2$ & 171 & 10 & 3.14 & 0.31 & 0.678 & 0.682 & 0.005 & NS \\
\hline Dg3 & 172 & 5 & 4.00 & 0.80 & 0.762 & 0.750 & -0.017 & NS \\
\hline Dg4 & 169 & 13 & 5.78 & 0.44 & 0.782 & 0.827 & 0.056 & NS \\
\hline Dg5 & 171 & 6 & 2.91 & 0.49 & 0.632 & 0.656 & 0.037 & NS \\
\hline Dg6 & 169 & 4 & 1.89 & 0.47 & 0.503 & 0.470 & -0.070 & NS \\
\hline All loci & & 7.33 & 3.23 & 0.44 & 0.621 & 0.629 & 0.012 & 0.0079 \\
\hline \multicolumn{9}{|l|}{ Saplings } \\
\hline$D g 1$ & 375 & 7 & 1.70 & 0.24 & 0.374 & 0.411 & 0.090 & NS \\
\hline$D g 2$ & 375 & 10 & 3.04 & 0.30 & 0.653 & 0.671 & 0.026 & 0.0117 \\
\hline Dg3 & 373 & 9 & 3.94 & 0.44 & 0.729 & 0.746 & 0.023 & 0.0199 \\
\hline$D g 4$ & 349 & 14 & 4.50 & 0.32 & 0.705 & 0.778 & 0.094 & 0.0003 \\
\hline Dg5 & 375 & 5 & 3.05 & 0.61 & 0.654 & 0.672 & 0.026 & NS \\
\hline Dg6 & 374 & 4 & 1.84 & 0.46 & 0.473 & 0.457 & -0.035 & NS \\
\hline All loci & & $8.17[7.40]^{a}$ & 3.01 & 0.37 & 0.598 & 0.623 & 0.037 & $<0.00001$ \\
\hline
\end{tabular}

$n$ : sample size, $A$ and $A_{\mathrm{e}}$ : observed and effective numbers of alleles per locus, $H_{\mathrm{o}}$ and $H_{\mathrm{e}}$ : observed and expected heterozygosities, $F_{\mathrm{IS}}$ : fixation index. Departure from Hardy-Weinberg equilibrium was tested by exact tests of Haldane (1954) and exact $P$-values were estimated (NS: $P>0.05)$.

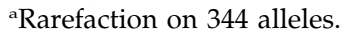

saplings, indicating that aggregation at the two levels is stronger in adults than in saplings.

Following these observations, the total population was subdivided into five aggregates for further genetic investigations, corresponding to an intermediate level of aggregation suggested by the $L$. function $(200-300 \mathrm{~m})$. The intermediate level was chosen as a compromise, and was also imposed as a constraint to maintain sufficient sample size per aggregate for testing differentiation among them. It does not necessarily correspond to a biological subdivision but should be seen as a first approach to test for spatial differentiation. There are a number of different ways to subdivide the population into aggregates of approximately $200-300 \mathrm{~m}$. We tested different subdivisions into five contiguous aggregates of about equal size, and the differentiation levels calculated were of similar magnitude in each case. For each subdivision tested, we compared the differentiation values to the value obtained by randomly assigning the genotypes to the trees distributed in the same spatial aggregates. As expected, the differentiation was near zero when genotypes were randomly redistributed.

\section{Genetic diversity within and between cohorts}

Allelic richness (Table 2) was lower for adults than for saplings (7.33 vs 8.17). However, after standardization using the rarefaction method, allelic richness was of the same magnitude in the two cohorts (7.33 vs 7.40). Observed heterozygosity displayed a similar range for adults (0.37-0.78) and saplings (0.37-0.73). This was also the case for expected heterozygosity: adults, 0.39-0.83 and saplings, $0.41-0.78$. Mean expected heterozygosities, were also similar (0.629 vs 0.623$)$ in the two cohorts, but observed heterozygosity was slightly higher in adults than saplings (0.621 vs 0.598). The frequency profiles were the same in the two cohorts and the most frequent alleles at each locus were shared by the two cohorts, (except Dg5, where two common alleles were present). The Student's $t$-test (used for allelic richness) and the $z$ - 
test (used for $H_{\mathrm{e}}$ and $H_{\mathrm{o}}$ ) confirmed that diversity was of similar magnitude in the two stage-classes over all loci.

The ratio $A_{\mathrm{e}} / A$ varied from 0.27 to 0.80 in the adult population (average $=0.44$ ), and from 0.24 to 0.61 in saplings (average $=0.37$ ). For the two cohorts only one locus exhibited a ratio greater than 0.50 ( $\mathrm{Dg} 3$ for adults and $D g 5$ for saplings). These values indicated an important heterogeneity of the allele frequency profiles; for most loci (except $D g 5$ ) there was one frequent allele and many rare alleles. Nevertheless, 11 private alleles (ie present in only one stage-class) were found over all loci, at which three were only present in adults. The three adult-specific alleles may not have been detected in the sapling class because all saplings were not genotyped (Figures 1 and 2) or because they have been lost because of genetic drift. On the other hand, the eight saplingspecific alleles reflect gene flow from outside the study plot.

There is a general trend towards an excess of homoqzygosity in adult and sapling populations, as indicated by the predominance of positive $F_{I S}$ values (Table 2). Deviation from Hardy-Weinberg equilibrium was more pronounced in the sapling cohort (three loci with significant deviations) than in the adults (only one locus with significant deviations). The fixation index ranged from -0.07 to +0.06 (adults) and from -0.04 to +0.09 (saplings); for multilocus analysis, a slight but significant heterozygote deficit was detected, which was higher for saplings than for adults (0.037 and 0.012, respectively). For chloroplast diversity (Table 3), the number of haplotypes was the same in the two cohorts $(A=3)$, and diversity was also of similar magnitude (0.59 vs 0.57). The three haplotypes were almost evenly distributed in the two cohorts $\left(A_{\mathrm{e}} / A=0.8\right)$.

\section{Generational vs spatial genetic structure}

To test for genetic differentiation between different age classes, the total population was subdivided into two different ways: between the two cohorts (adults and saplings) and within the adult cohort there was an additional subdivision into three classes according to diameter distribution.

Table 3 Chloroplast diversity statistics

\begin{tabular}{lllll}
\hline Cohort & $A$ & $A_{e}$ & $A_{e} / A$ & $H_{S}$ \\
\hline Adult & 3 & 2.43 & 0.81 & 0.588 \\
Sapling & 3 & 2.30 & 0.77 & 0.565
\end{tabular}

A: Haplotypic richness; $A_{\mathrm{e}}$ : effective number of haplotypes; $H_{\mathrm{S}}$ : within-population diversity.
Whatever the generational subdivision used, F-statistics showed that differentiation among groups was extremely low (Table 4), and the total fixation index was of the same magnitude within each age class. The lack of generational differentiation was also observed for chloroplast markers (Table 5).

These results contrast with the spatial differentiation. Adult and sapling cohorts were subdivided into five patches (Figure 1). There was a significant differentiation among patches in both adult and sapling cohorts, with $\mathrm{F}_{\mathrm{ST}}$ values ranging from 0.02 to 0.03 for nuclear markers (Table 4) and from 0.29 to 0.42 for chloroplast markers (Table 5 and Figure 4). The differentiation remained significant when $\mathrm{F}_{\mathrm{ST}}$ values were calculated for pairs of patches (all pairwise values for saplings, and 8/10 pairwise values for adults).

The spatial differentiation among patches was further confirmed by spatial autocorrelation analysis. There was a clear trend of significant positive autocorrelations at short distances for each SSR locus, despite interlocus variation (Figure 5). This trend was also supported by multilocus analysis. The correlogram for nuclear data (Figure 6), showed a significant nonrandom distribution of genotypes at short distances (approximately less than $110 \mathrm{~m}$ ) for both cohorts. Moran's index for the adult cohort was larger than for the sapling one (0.18 vs 0.08) within the first distance-class. As expected, considering differentiation values, the chloroplast autocorrelations were larger than the nuclear ones at short distances for adults (0.9 vs 0.18 , respectively) and for saplings (0.7 vs 0.08 , respectively). For adults, the autocorrelations were also significant over larger distances for cpDNA (up to $140 \mathrm{~m}$ ) than for nuclear DNA (up to $110 \mathrm{~m}$ ). The same trend was observed for the saplings. Hence, these analyses show that spatial genetic structure is more

Table 5 Diversity statistics of chloroplast genetic marker

\begin{tabular}{lcccc}
\hline Subdivision & $\mathrm{H}_{S}$ & $\mathrm{H}_{T}$ & $\mathrm{G}_{S T}$ & P-value \\
\hline Generational & & & & \\
$\quad$ Adult/sapling & 0.577 & 0.575 & 0.003 & $\mathrm{NS}$ \\
$\quad$ Diameter classes of adults & 0.587 & 0.588 & 0.001 & $\mathrm{NS}$ \\
& & & & \\
Spatial & & & & \\
$\quad$ Adult aggregates & 0.398 & 0.686 & 0.419 & $<0.0001$ \\
$\quad$ Sapling aggregates & 0.464 & 0.649 & 0.285 & $<0.0001$ \\
\hline
\end{tabular}

$H_{\mathrm{S}}$ : Within-subpopulation; $H_{\mathrm{T}}$ : total gene diversities; $G_{\mathrm{ST}}$ : coefficient of gene differentiation. $\chi^{2}$ test $P$-values from allelic frequencies were estimated by Haploid software (NS: $P>0.05$ ).

Table 4 F-statistics for generational and spatial subdivisions

\begin{tabular}{|c|c|c|c|c|c|c|}
\hline Subdivision & $\mathrm{F}_{I T}$ & P-value & $\mathrm{F}_{S T}$ & P-value & $\mathrm{F}_{I S}$ & P-value \\
\hline \multicolumn{7}{|l|}{ Generational } \\
\hline Adult/Sapling & $0.036 \pm 0.019$ & $<0.0005$ & $0.005 \pm 0.003$ & $<0.0005$ & $0.032 \pm 0.018$ & 0.003 \\
\hline Diameter classes & $0.014 \pm 0.018$ & NS & $0.0001 \pm 0.002$ & NS & $0.014 \pm 0.019$ & NS \\
\hline \multicolumn{7}{|l|}{ Spatial } \\
\hline Adult aggregates & $0.021 \pm 0.018$ & NS & $0.029 \pm 0.006$ & $<0.0005$ & $-0.008 \pm 0.019$ & NS \\
\hline Sapling aggregates & $0.046 \pm 0.018$ & $<0.0005$ & $0.021 \pm 0.006$ & $<0.0005$ & $0.025 \pm 0.018$ & 0.0365 \\
\hline
\end{tabular}

Standard deviations of Weir and Cockerham (1984), F-statistics by jack-knifing over loci. Tests over-all loci were performed for each statistic and $P$-values were estimated by permutations (NS: $P>0.05$ ). 


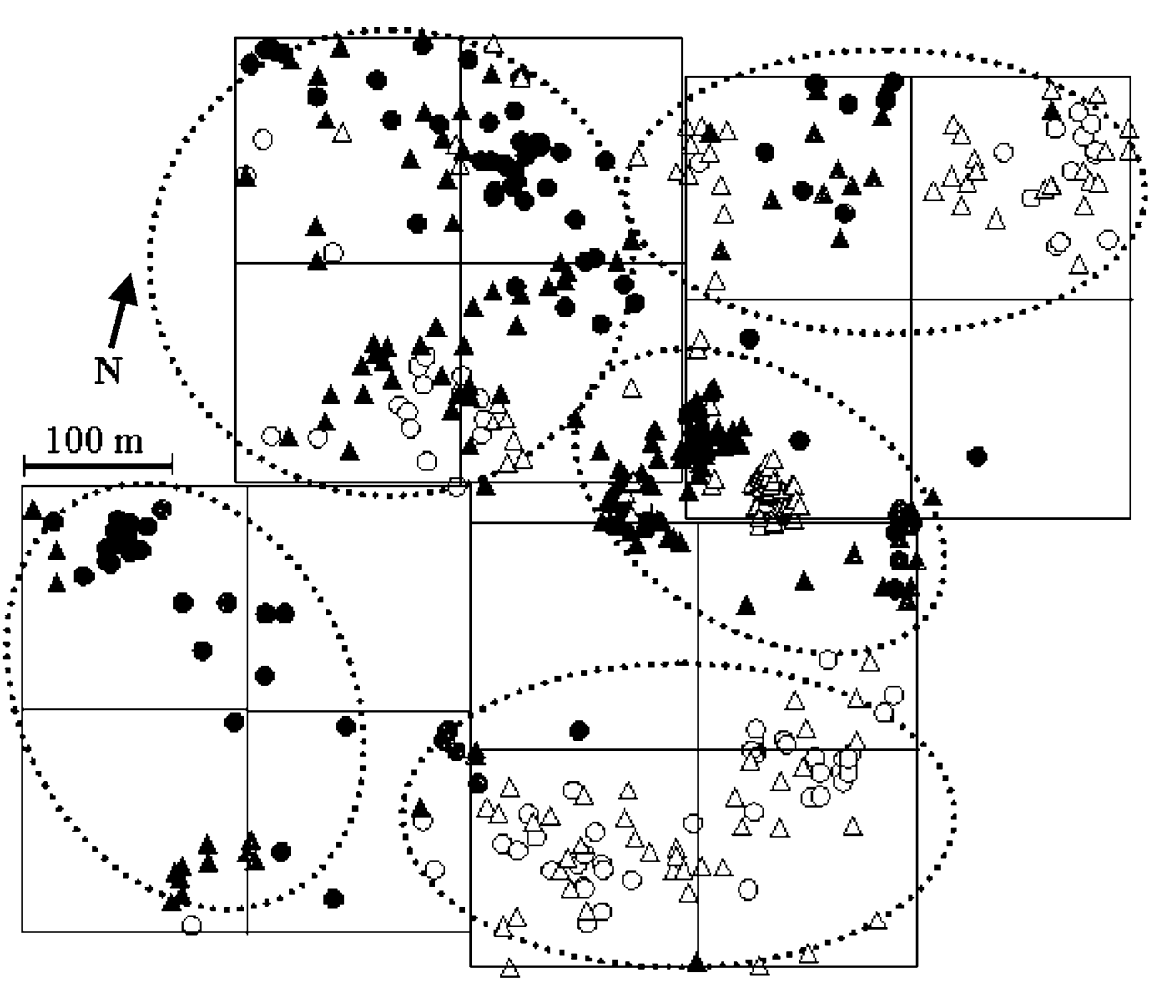

Figure 4 Spatial distribution of the cpDNA haplotypes in the two cohorts. Each of the three haplotypes is represented by a shaded (white, black, and grey) symbol, for the adults $(\bullet)$ and the saplings $(\Delta)$. Borders of the aggregates are in dotted lines.

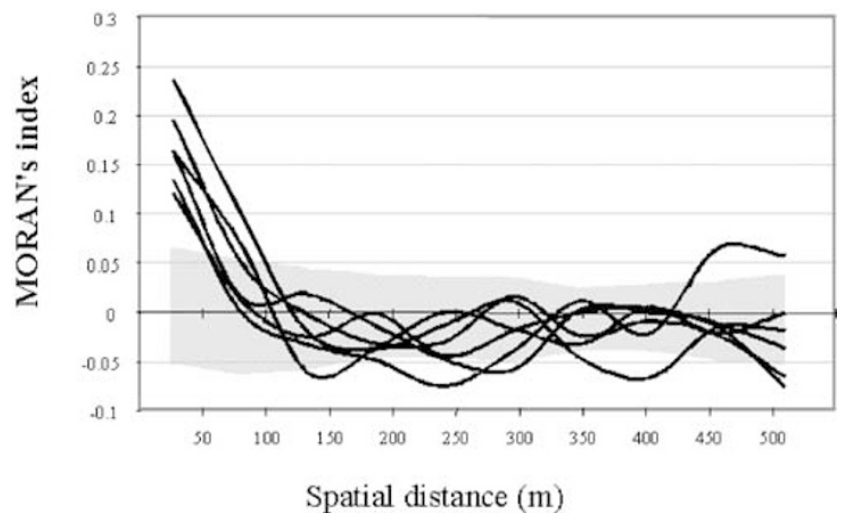

Figure 5 Spatial genetic autocorrelation for the six microsatellite loci in the adult cohort. Each solid line corresponds to the observed data for one locus. The grey area corresponds to the $95 \%$ confidence interval envelope calculated by 500 Monte-Carlo simulations.

pronounced for chloroplast markers than nuclear markers. Significant negative values of Moran's index at distances larger than $250 \mathrm{~m}$ suggest that pairs of trees are less genetically similar than expected. Indeed, they always exhibit different haplotypes when they are compared at these distances. This is also confirmed by the high $G_{\mathrm{ST}}$ values for cpDNA among patches (Table 5).

\section{Discussion}

Spatial genetic and demographic genetic structures suggest efficient and rapid colonization dynamics

The data of this study confirm the aggregated spatial distribution of trees of D. guianensis, even though a precise size of aggregates is not clearly shown by the $L$-function. The variation of the $L$-function rather suggested various possible aggregates ranging in size from 100 to $400 \mathrm{~m}$, with peak values reached at these extremes. Interestingly, the same pattern of spatial distribution was observed in the two cohorts of adults and saplings. Previous demographic studies estimated an average area of aggregates of 0.9 ha (ie a circle of radius $50 \mathrm{~m}$ ) at the same field site (Eymond, 1992), which correspond to the lower level of aggregation detected here. Goreaud et al (1997) found two smaller peaks (50 and $150 \mathrm{~m}$ ) but they discarded marsh and low-ground zones in their survey; unfavourable environments for $D$. guianensis (Kokou, 1992). The lower level of aggregation $(100 \mathrm{~m}$ or below), groups trees that are very similar genetically, as suggested by the spatial autocorrelation analysis (Figure 6), and illustrated by the spatial distribution of cpDNA haplotypes (Figure 4). Hence, there is strong correspondence between demographic and spatial genetic structure in small distance classes.

The congruence between the demographic and genetic structures is likely to be the consequence of restricted seed dispersal, meaning that the smaller size of aggregates would correspond to the dispersion distance from a single source (ie maternal tree). Larger demographic aggregates most probably result from dispersion of seeds originating from different sources (Figure 4). They could also be constituted by an assemblage of smaller aggregates. As a result, chloroplast variation in large aggregates is more diverse than small ones, even though a significant genetic differentiation between larger aggregates can still be observed (Table 4). An interesting feature of these dynamics is that they permit high levels of diversity to be maintained. It is striking to 

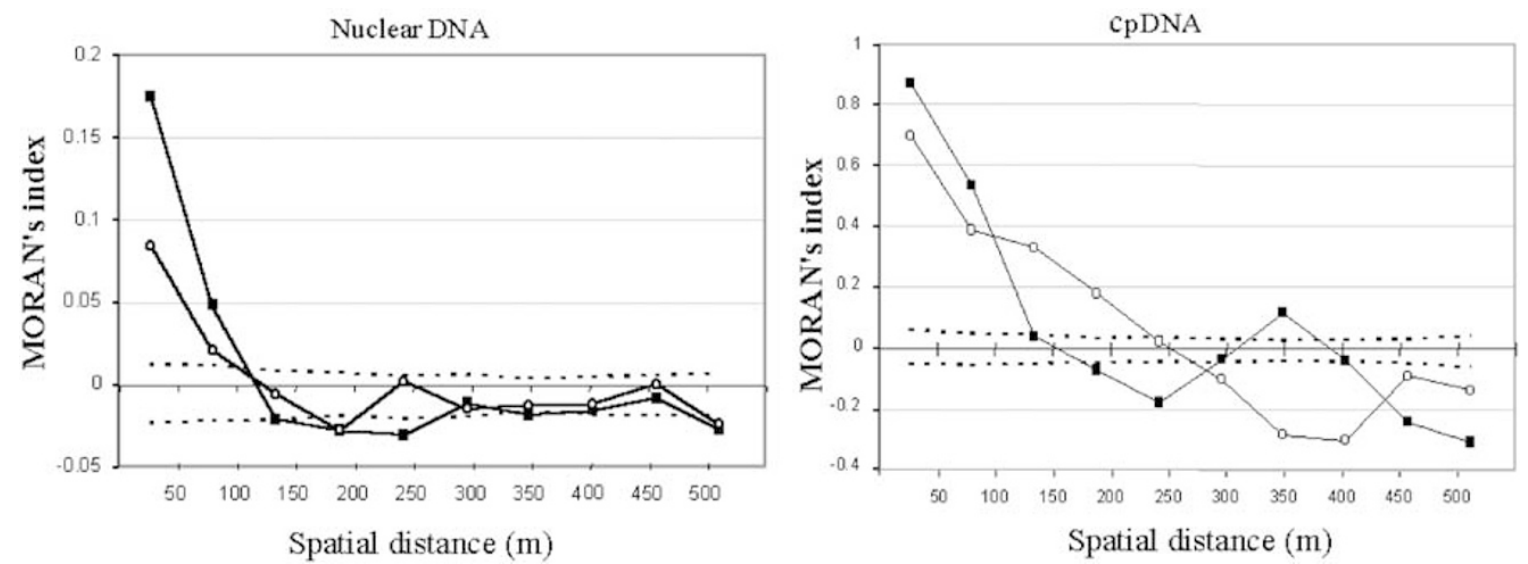

Figure 6 Spatial genetic autocorrelation for cpDNA markers and six microsatellite loci in the two cohorts. Moran's indexes were calculated in the adult cohort $(\mathbf{a})$ and in the sapling cohort $(\square)$. The solid line corresponds to observed data. The two dotted lines correspond to the 95\% confidence interval envelope of calculated by 500 Monte-Carlo simulations.

observe that the level of cpDNA diversity within and between larger aggregates in our study is of the same magnitude as the level observed within and between different stands across French Guiana (Caron et al, 2000).

Maintenance of diversity requires that the founders of different aggregates were diverse, and that the time elapsed since foundation was too short to allow erosion of diversity by drift. Genetic multiplicity of founders is expected for species that have a composite dispersion mechanism, such as diffusion and rare long distance dispersal (Le Corre et al, 1997). An avoidance of fixation of haplotypes is expected in recently formed aggregates for a colonizing species or in nonequilibrium situations where aggregates are ephemeral in time and are subject to rapid extinction-recolonization dynamics. Our results fit within current knowledge about the efficient colonizing ability of Dicorynia. Seeds could germinate in shade or luminous environment (Meer et al, 1998) but saplings need light to grow (Forget, 1988). The species is known to be opportunistic and rapidly colonizes gaps that occur because of accidental trees falls, except in marsh and low-ground zones (Kokou, 1992).

\section{Comparative analysis of spatial nuclear and cytoplasmic} genetic structure indicates asymmetry of pollen and seed flow

Nuclear and cytoplasmic autocorrelations show similar patterns and were significant only over short distances (ie less than $100 \mathrm{~m}$ ). However, there is an important difference in absolute values of Moran's index between these genomes, as $I$ values approach 0.9 at $50 \mathrm{~m}$ for cpDNA and 0.18 for nuclear genes (Figure 6). These data suggest that the fine-scale spatial genetic structure is mainly the consequence of restricted seed dispersal, and that pollen flow has limited impact. These conclusions are also supported by the coexistence of low fixation index at the whole population level and significant genetic relatedness at short distances (shown by the significant $I$ values). Genetic relatedness at short distances is therefore likely to result from uniparental relations (half-sibs) rather than biparental relations (full sibs). Hence, neighbouring trees most probably share only one parent in common (the maternal), the male parent being more distantly located. We may therefore conclude that the comparative analysis of fine-scale nuclear and cytoplasmic spatial structure suggests a strong asymmetry between pollen and seed flow. These results can be compared to the current knowledge of the dispersion mechanisms of the species. Seeds of $D$. guianensis are thought to be wind-dispersed with pollen dispersed by Hymenoptera species (Caron et al, 1998). Previous studies have found average and maximum distances of seed dispersal of 30 and $60 \mathrm{~m}$, respectively, based on seed tagging experiments (Forget, 1988). The maximum distance of effective pollen flow evaluated so far for D. guianensis was $200 \mathrm{~m}$ as inferred by the spatial distributions of rare allozymes (Caron et al, 1998). Our genetic results support the biological observations suggesting that pollen is dispersed over larger distances than seeds, resulting in a stronger genetic structure for chloroplast markers than nuclear markers.

\section{Changes of genetic structures between the juvenile and} adult cohort

In this study, $D$. guianensis exhibited similar levels of microsatellite diversity $\left(H_{\mathrm{e}}=0.63\right)$ to other neotropical tree species, Vouacapoua americana $\left(H_{\mathrm{e}}=0.5\right.$, Dutech, 2001) Swietenia humilis $\left(H_{\mathrm{e}}=0.546\right.$, White and Powell, 1997), and Pithecellobium elegans $\left(H_{\mathrm{e}}=0.64\right.$, Chase et al, 1996) but lower than in Symphonia globulifera $\left(H_{\mathrm{e}}=0.83\right.$, Aldrich et al, 1998). The computation of diversity and differentiation statistics has shown that allelic frequencies (either for nuclear or cytoplasmic markers) are more differentiated among aggregates than among cohorts, and has been commented on earlier as the result of dispersion and colonization dynamics of Dicorynia guianensis.

Fixation indices and genetic autocorrelation showed clear genetic structure differences between adult and sapling cohorts. Fixation indices for SSRs were significant for both cohorts, but indicated a higher heterozygote deficiency for the saplings than for the adult trees. This was found in other species comparing different cohorts (review in Murawski, 1995). Maintenance of positive fixation indices in the adult cohort may be the consequence of the tolerance of selfing by Dicorynia 
(Caron et al, 1998), or the existence of Wahlund effects caused by generation overlapping in the adult cohort. As already mentioned, the adult cohort was composed of trees exhibiting a wide range of dimensions ( $\mathrm{DBH}$ varying between 20 and $50 \mathrm{~cm}$ ) and may be composed of two or even three generations. The decrease of fixation index in the adults may result from the preferential elimination of selfed trees because of the high selection pressures in dense tropical tree forests. More interesting is the reinforcement of spatial genetic structure in the adult cohort at short distances (less than $100 \mathrm{~m}$ ), as compared to saplings, despite the decrease of the fixation index between sapling and adult cohort. The stronger genetic relations between neighbouring adults was shown for both nuclear and cpDNA markers (Figure 6). Overlapping of generations within the adult cohort could be invoked as one hypothesis, suggesting that neighbouring trees may actually be a mixture of parents and offspring. However, when the autocorrelations were computed within separate diameter classes, Moran's index for all adult subgroups remained larger than the saplings (data not shown). Hence, stronger genetic relatedness was present within a given generation. A likely explanation to this observation is selection. If the competitive ability is highly heritable, then selection may favour progenies that share this ability, and within a given neighbourhood only offspring of these progenies will survive to the adult stage.

\section{Acknowledgements}

This study was carried out with the financial support from ECOFOR (Project 'Régénération de l'Angélique (Dicorynia guianensis (Amshoff)) en Guyane française'). We are very grateful to CIRAD-forêt and particularly to $S$ Gourlet-Fleury, T Perrot and S Jésel for access to field site, for providing mapping data and for valuable discussions about $D$. guianensis. We also thank SO Cazal for his helpful technical assistance and $S$ OddouMuratorio, F Austerlitz and $\mathrm{O}$ Hardy for all their good advices.

\section{References}

Aldrich PR, Hamrick JL, Chavarriaga P, Kochert G (1998). Microsatellite analysis of demographic genetic structure in fragmented populations of the tropical tree Symphonia globulifera. Mol Ecol 7: 933-944.

Bariteau M (1993). La régénération naturelle avant et après exploitation sur le dispositif d'expérimentation sylvicole de Paracou en Guyane Française. PhD Thesis, University of Paris VI, Paris.

Bena P (1960). Essences forestières de Guyane, Bureau agricole et forestier guyanais, Imprimerie nationale: Paris.

Besag J (1977a). Contribution to the discussion of Dr Ripley's paper. JR Stat Soc B39: 193-195.

Besag J (1977b). Simple Monte Carlo tests for spatial pattern. Appl Statist 26: 327-333.

Cabrera-Gaillard C, Gignoux J (1990). Répartitions spatiales et sylviculture en forêt guyanaise. Internal report, CIRAD Kourou, p 19.

Caron H, Dumas S, Marque G, Messier C, Bandou E, Petit RJ et al (2000). Spatial and temporal distribution of chloroplast DNA polymorphism in a tropical tree species. Mol Ecol 9: 1089-1098.

Caron H, Dutech C, Bandou E (1998). Spatio-temporal variation in the mating system of Dicorynia guianensis Amshoff
(Caesalpiniaceae) in Guianan forest [French]. Genet Sel Evol 30: S153-S166.

Chase M, Kesseli R, Bawa K (1996). Microsatellite markers for population and conservation genetics of tropical trees. Am J Bot 83: 51-57.

Degen B, Petit R, Kremer A (2001). SGS-Spatial Genetic Software: a computer program for analysis of spatial genetic and phenotypic structures of individuals and populations. J Hered 92: 447-449.

Doyle JJ, Doyle JL (1990). Isolation of plant DNA from fresh tissue. Focus 12: 13-15.

Dumolin S, Demesure B, Petit RJ (1995). Inheritance of chloroplast and mitochondrial genomes in pedunculate oak investigated with an efficient PCR method. Theor Appl Genet 91: 1253-1256.

Dumolin-Lapègue S, Pemonge MH, Petit RJ (1997a). An enlarged set of consensus primers for the study of organelle DNA in plants. Mol Ecol 6: 393-397.

Dumolin-Lapègue S, Pemonge MH, Petit RJ (1997b). Association between chloroplast and mitochondrial lineages in oaks. Mol Biol Evol 15: 1321-1331.

Dutech C (2001). Diversité génétique et dynamique de la forêt tropicale humide: le cas d'une espèce ligneuse guyanaise, Vouacapoua Americana (Caesalpiniaceae). PhD Thesis, Université de Montpellier II.

El-Mousadik A, Petit RJ (1996). High level of genetic differentiation for allelic richness among populations of the argan tree (Argania spinosa (L.) Skeels) endemic to Morocco. Theor Appl Genet 92: 832-839.

Ennos RA (1994). Estimating the relative rates of pollen and seed migration among plant populations. Heredity $\mathbf{7 2}$ 250-259.

Eymond V (1992) Régénération naturelle de l'angélique: Dicorynia guianensis sur le dispositif sylvicole de Paracou (Guyane française). Master Thesis ENGREF, Montpellier.

Forget PM (1988). Dissémination et régénération naturelle de huit espèces d'arbres en forêt guyanaise. $\mathrm{PhD}$ Thesis, University of Paris VI, Paris.

Goreaud F, Courbaud B, Collinet F (1997). Spatial structure analysis applied to modelling of forest dynamics: a few examples. In: Amaro A, Tomé $\mathrm{M}$ (eds) Proceedings of the IUFRO Workshop: Empirical and Process Based Models for Forest Tree and Stand Growth Simulation, Salamandra Press: Lisbon, Portugal. pp 155-172.

Goudet J (1995). FSTAT (Version 1.2): a computer program to calculate F-statistics. J Hered 86: 485-486.

Goudet J, Raymond M, Meeus TD, Rousset F. (1996). Testing differentiation in diploid populations. Genetics 144: 1933-1940.

Guo SW, Thompson EA (1992). Performing the exact test of Hardy-Weinberg proportion for multiple alleles. Biometrics 48: 361-372.

Haldane JBS (1954). An exact test for randomness of mating. $J$ Genet 52: 631-635.

Kokou K (1992). Contribution à l'étude du déterminisme écologique de la répartition spatiale de l'Angélique (Dicorynia guianensis) en forêt guyanaise. Master Thesis, ENGREF and Université Bordeaux II.

Latouche-Hallé C, Ramboer A, Bandou E, Caron H, Decroocq S (2002). Isolation and characterization of microsatellite markers in the tropical tree species Dicorynia guianensis (Caesalpinaceae). Mol Ecol Notes 2: 228-230.

Latouche-Hallé C, Ramboer A, Bandou E, Caron H, Kremer A (2003). Long distance pollen flow and heterogeneous male mating success in a neotropical tree species. (submitted).

Le Corre Vl, Machon N, Petit RJ, Kremer A (1997). Colonization with long-distance seed dispersal and genetic structure of maternally inherited genes in forest trees: a simulation study. Genet Res 69: 117-125.

Meer PJ, van de Sterck FJ, Bongers F (1998). Tree seedling performance in canopy gaps in a tropical rain forest at Nouragues, French Guiana. J Trop Ecol 14: 119-137. 
Murawski DA (1995). Reproductive biology and genetics of tropical trees from a canopy perspective. In: Lowman MD, Nadkarni NM (eds) Forest Canopies, Academic Press, San Diego, CA, pp 457-493.

Nei M (1987). Molecular Evolutionary Genetics. Columbia University Press: New York.

Pelissier R, Goreaud F (2001). A practical approach to the study of spatial structure in simple cases of heterogeneous vegetation. J Veg Sci 12: 99-108.

Pons O, Petit RJ (1995). Estimation, variance and optimal sampling of gene diversity. I. Haploid locus. Theor Appl Genet 90: 462-470.

Raymond M, Rousset F (1995). An exact test for population differentiation. Evolution 49: 1280-1283.

Ripley BD (1976). The second-order analysis of stationary point process. J Appl Probab 13: 255-266.

Sabatier D, Prevost MF (1990). Quelques données sur la composition floristique et la diversité des peuplements forestiers de Guyane Française. Bois For Trop, Spécial Guyane 219: 31-55.

Schmitt L, Bariteau M (1990). Management of the forest ecosystem of French Guiana: study of growth and natural regeneration in the Paracou research area. [French]. Bois For Trop 220: 3-23.

Sokal RR, Rohlf FJ (1994). Biometry, 3rd edn. Freeman: San Francisco, CA

Streiff R, Ducousso A, Lexer C, Steinkellner H, Gloessl J, Kremer A (1999). Pollen dispersal inferred from paternity analysis in a mixed oak stand of Quercus robur L. and $Q$. petraea (Matt.) Liebl. Mol Ecol 8: 831-841.

Streiff R, Labbe T, Bacilieri R, Steinkellner H, Glossl J, Kremer A (1998). Within-population genetic structure in Quercus robur L. and Quercus petraea (Matt.) Liebl. assessed with isozymes and microsatellites. Mol Ecol 7: 317-328.

Thioulouse J, Chessel D, Doledec S, Olivier JM (1997). ADE-4: a multivariate analysis and graphical display software. Statist and Comput 7: 75-83.

Weir BS, Cockerham CC (1984). Estimating F-statistics for the analysis of population structure. Evolution 38: 1358-1370.

White G, Powell W (1997). Isolation and characterization of microsatellite loci in Swietenia humilis (Meliaceae): an endangered tropical hardwood species. Mol Ecol 6: 851-860. 